\title{
Improved thermal and strain performance of annealed polymer optical fiber Bragg gratings
}

Yuan, Scott Wu; Stefani, Alessio; Bache, Morten; Jacobsen, Torben; Rose, Bjarke; Herholdt-Rasmussen, Nicolai; Nielsen, Finn Kryger; Andersen, Søren; Sørensen, Ole Brødsted; Hansen, Knud Styhr

Total number of authors:

11

Published in:

Optics Communications

Link to article, DOI:

10.1016/j.optcom.2010.08.069

Publication date:

2011

Document Version

Peer reviewed version

Link back to DTU Orbit

Citation (APA):

Yuan, S. W., Stefani, A., Bache, M., Jacobsen, T., Rose, B., Herholdt-Rasmussen, N., Nielsen, F. K., Andersen, S., Sørensen, O. B., Hansen, K. S., \& Bang, O. (2011). Improved thermal and strain performance of annealed polymer optical fiber Bragg gratings. Optics Communications, 284(1), 176-182.

https://doi.org/10.1016/j.optcom.2010.08.069

\section{General rights}

Copyright and moral rights for the publications made accessible in the public portal are retained by the authors and/or other copyright owners and it is a condition of accessing publications that users recognise and abide by the legal requirements associated with these rights.

- Users may download and print one copy of any publication from the public portal for the purpose of private study or research.

- You may not further distribute the material or use it for any profit-making activity or commercial gain

- You may freely distribute the URL identifying the publication in the public portal 


\title{
Improved thermal and strain performance of annealed polymer optical fiber Bragg gratings
}

\author{
Wu Yuan ${ }^{1, *}$, Alessio Stefani ${ }^{1}$, Morten Bache ${ }^{1}$, Torben Jacobsen ${ }^{2}$, Bjarke Rose ${ }^{2}$, Nicolai Herholdt- \\ Rasmussen $^{2}$, Finn Kryger Nielsen ${ }^{3}$, Søren Andresen ${ }^{3}$, Ole Brøsted Sørensen ${ }^{4}$, \\ Knud Styhr Hansen ${ }^{4}$, Ole Bang ${ }^{1}$ \\ ${ }^{1}$ DTU Fotonik, Dept. of Photonics Engineering, Technical University of Denmark, \\ DK-2800 Kgs. Lyngby, Denmark \\ wyuan@fotonik.dtu.dk \\ ${ }^{2}$ Ibsen Photonics A/S, Ryttermarken 15-21, DK-3520, Far $\mu$, Denmark \\ ${ }^{3}$ Brüel \& Kjær Sound \& Vibration Measurements A/S, Skodsborgvej 307, \\ DK-2850 Nærum, Denmark \\ ${ }^{4}$ DPA Microphones A/S, Gydevang 42-44, DK-3450 Allerød, Denmark
}

\begin{abstract}
:
We report on a detailed study of the inscription and characterization of fiber Bragg gratings (FBGs) in commercial step index polymer optical fibers (POFs). Through the growth dynamics of the gratings, we identify the effect of UV-induced heating during the grating inscription. We found that FBGs in annealed commercial POFs can offer more stable short-term performance at both higher temperature and larger strain. Furthermore, the FBGs' operational temperature and strain range without hysteresis was extended by the annealing process. We identified long-term stability problem of even the annealed POF FBGs.
\end{abstract}

Keywords: Fiber Bragg grating, polymer optical fiber

\section{Introduction}

Fiber Bragg gratings have been written in many types of POFs, for example polymethyl methacrylate (PMMA) POFs [1-14], fluorinated POFs [15, 16], and TOPAS POFs [17], by using various methods such as phasemask [1-5], direct writing [6], or a combination of phase mask and interferometry [7-16]. 325nm has been employed as a mainstream wavelength for writing grating in PMMA POFs [1-5, 8-15]. Other wavelength such as $355 \mathrm{~nm}$ obtained from a frequency-tripled Nd:YAG laser has been used to write grating in CYTOP fiber developed by Asahi Glass Co. and Keio University $[15,16]$. On the other hand, 800nm femtosecond pulses from Ti:Sapphire laser or its double frequency was mainly used for point by point direct writing [6] or grating writing with a phasemask [7].

However, the mechanism of index change does not appear to be fully understood [5, $13,18-20]$. It is believed that more than one process is involved in the photo-induced refractive index changes and hence in the grating formation dynamics [18-20]. The widely accepted point is that the principle mechanism of index change is an increase due to the photo-induced polymerization of the unreacted monomers [5, 18-20], while laser-induced heating in the irradiated region during the inscription may also contribute to the index change [5]. Previous reports indicated that annealing of the POF before FBG inscription can relieve the frozen-in stress induced by the fiber drawing process [21] and increase the linear operation temperature range of FBGs [22]. However, the effect of annealing on the strain sensitivity performance was not yet considered.

Polymer optical FBGs have shown great potential for sensor applications to sense for example temperature and strain with higher sensitivity and wider tunability than its silica counterpart [1-14]. Those advantages are due to the lower Young's modulus and higher thermo-optic coefficient of POFs [23, 24]. In addition, polymers are clinically 
acceptable, which along with the flexible, non-brittle nature of the fibers makes these gratings an important candidate for in-vivo biosensing applications [25-28]. Despite of these promises not many commercial applications have been realized yet due to the high material loss of POFs. Here we consider fiber-optical accelerometers and microphones from a commercial point of view. In our applications we need a short length of POF to increase the sensitivity-frequency range product of the transducer and we opt for a commercial single mode POF to potentially have a reliable supply. This means that we are interested in both the strain sensitivity and the temperature stability of POF FBG and how to improve the operation regime.

In this paper we report on an investigation into UV-written FBGs in commercial stepindex POFs. The formation dynamics, the temperature response, the thermal stability, and the tensile strain features of the gratings in both annealed and non-annealed POFs are studied and compared. We show that the FBGs in the annealed POFs can offer more stable short-term performance at both higher temperature and larger strain. Furthermore their operational temperature and tensile strain range without hysteresis can be extended using the annealing process. We also reveal the thermal effect of UVinduced heating during the grating formation. Finally the temperature stability measurements show that even the annealed POF FBGs have the long-term stability problem, when operated at high temperature.

\section{Experiments}

\subsection{POFs and FBGs Writing}

The gratings in this study were fabricated in PMMA single mode POF with a core doped with Polystyrene (MORPOF02 from Paradigm Optics). The fiber has an outside diameter of $115 \mu \mathrm{m}$ and an average core diameter of $4 \mu \mathrm{m}$. The numerical aperture (NA) of this POF at $1300 \mathrm{~nm}$ is about 0.27 according to the specs. The annealing is carried out by placing the POF in an oven at $80^{\circ} \mathrm{C}$ for two days. The fiber length decreased to $(98.7 \pm 0.5) \%$ of its original value over the 48 hours period and the diameter of the fiber increased to $(104.3 \pm 1) \%$ of its original value. So its V value at $1300 \mathrm{~nm}$ changed from 2.2 to 2.3 by the annealing.

The gratings were inscribed using a $30 \mathrm{~mW} \mathrm{CW} \mathrm{HeCd}$ laser operating at $325 \mathrm{~nm}$ (IK5751I-G, Kimmon). The fiber was supported by v-grooves on both sides with a gap in between to avoid reflection, and it was appropriately stretched to ensure that the fiber did not sag. A circular Gaussian laser beam was expanded from diameter 1.2 $\mathrm{mm}$ to $1.2 \mathrm{~cm}$ in one direction along the fiber by a cylindrical lens. The laser beam was then focused vertically downwards into the fiber core using another cylindrical lens to expose the fiber through a phase mask customized for $325 \mathrm{~nm}$ writing with a uniform period of $1048.7 \mathrm{~nm}$ chosen for $1550 \mathrm{~nm}$ grating inscription (Ibsen Photonics). A grating length of $3 \mathrm{~mm}$ was defined by a pinhole underneath the focus lens to control the beam width. The laser irradiance at the fiber was about $10 \mathrm{Wcm}^{-2}$ and the exposure time was usually over 60 minutes. The resulting grating wavelength was around $1553 \mathrm{~nm}$.

The growth of the $3 \mathrm{~mm}$ gratings were monitored in reflection during the inscription using a silica fiber circulator, a superK Versa broadband source (NKT Photonics) and an optical spectrum analyzer (Ando AQ6317B). A standard SMF-28 silica fiber was butt-coupled to the POF using an angle cleaved end-facet and a small amount of refractive index matching gel in order to reduce Fresnel reflections, which manifested themselves as background noise. The ends of the POF were prepared using a homemade hot blade cleaver equipped with flat side blade, which gives a high quality end facet, e.g., avoiding the problem of fiber core shifting [29]. Short lengths of fiber 
$(<10 \mathrm{~cm})$ were used due to the high attenuation of the POF, which is about $3 \mathrm{~dB} / \mathrm{cm}$ at $1550 \mathrm{~nm}$ according to the specs. The high loss around this operating wavelength makes the monitoring of the gratings in transmission extremely troublesome. The typical reflection spectra of a $3 \mathrm{~mm}$ grating fabricated in the annealed POF with different exposure time is shown in Fig.1 (a). Our POF FBG has about $2.5 \mathrm{~cm}$ fiber before the $3 \mathrm{~mm}$ grating starts. The field penetrates only a a short length into the grating, so a total length, forth and back, of about $5 \mathrm{~cm}$ is reasonable. This gives a total material loss of $15 \mathrm{~dB}$. The reflection normalized to the output of our broadband SuperK source has a maximum of about $-20 \mathrm{~dB}$ according to Fig. 1(a). The coupling loss is difficult to estimate, but at least $3 \mathrm{~dB}$ is to be expected, which would give a peak reflectance of more than $63 \%(-2 \mathrm{~dB})$.

It was also found that the side-lobes started to appear in the reflection spectrum at 70 minutes.

The growth dynamics of the gratings, i.e. the time dependent resonance wavelength, peak intensity, and bandwidth, are shown in Fig.1 (b-d). We note that the results shown in Fig. 1(b) are for a different (but identical) FBG than the results shown in Figs. 1(a) and 1(c-d). We found that the gratings inscribed into both the annealed and non-annealed POF follow an almost similar growth procedure. Both begin with a growth in strength accompanied by an almost constant grating bandwidth. After a certain time threshold, which is around 60 minutes, the grating strength saturates while the grating bandwidth increases rapidly. Figure 1(a) further shows that in this second regime the expected sidebands of a uniform grating starts to appear. This confirms the Type-I and Type-II FBG writing regimes known from silica FBG writing and shown to apply to POF FBG's also by Liu et al. [13]. Simultaneously, the resonance wavelength was shifting to the blue side, until after about 120 minutes, where a stable resonance wavelength was reached.
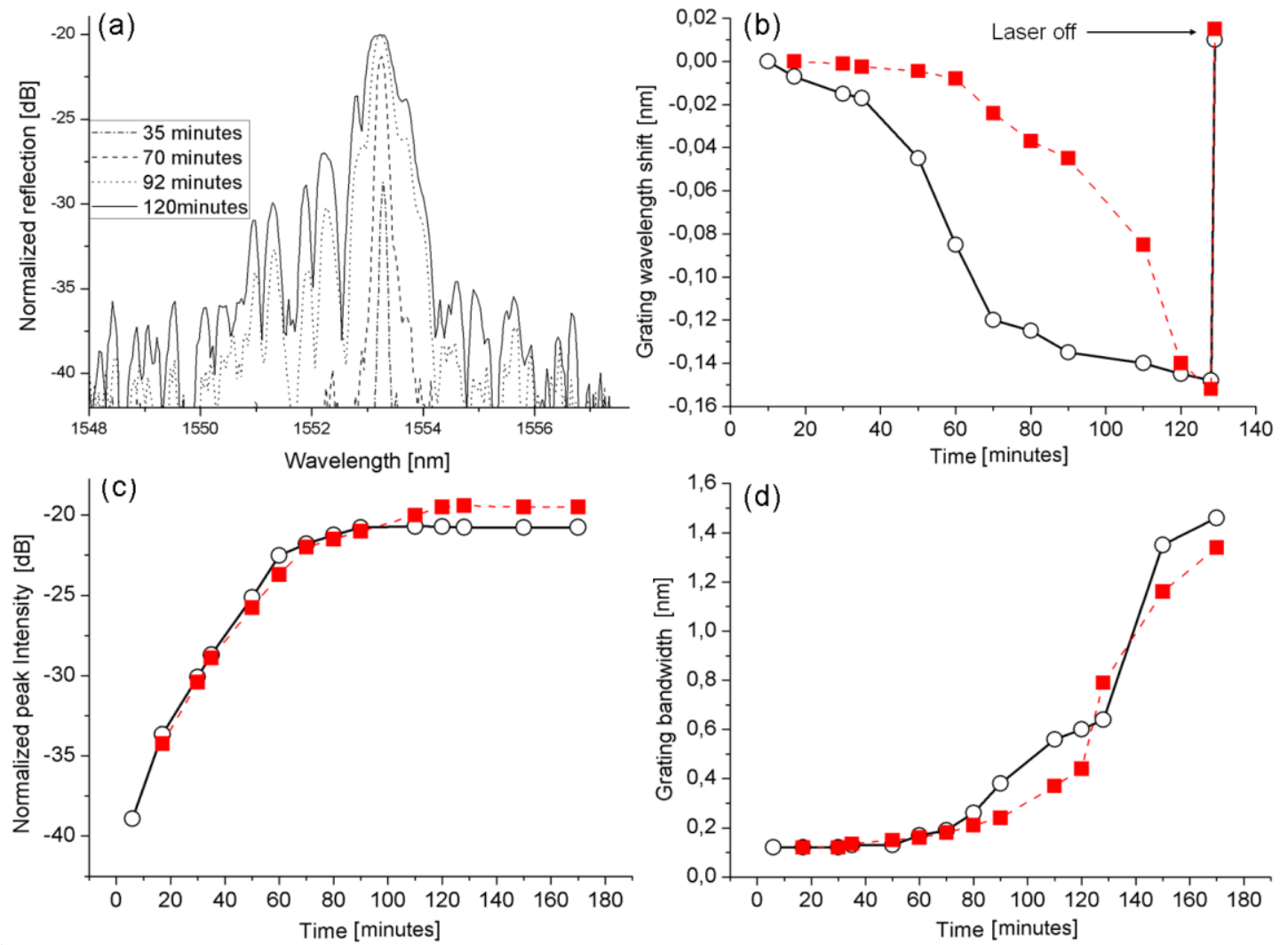
Figure 1. (a) Reflection spectra of a $3 \mathrm{~mm}$ FBG in an annealed POF at different writing time. (b-d) Growth dynamics of the $3 \mathrm{~mm}$ FBG in non-annealed POF (squares, dashed line) and annealed POF (circles, solid line). (b) Grating wavelength shift, (c) normalized peak intensity, (d) grating bandwidth. Measurements preformed in reflection.

The refractive index increase in PMMA induced by a $325 \mathrm{~nm}$ laser is mainly due to the material compaction or density increase in the laser-irradiated region, which results from the photo-induced polymerization of unreacted monomers [18-20]. UVinduced heating in the irradiated region during focused laser inscription may contribute to a permanent index increase [5], but this happens only when the local temperature is beyond some shrinking threshold, which is determined by the thermal history of the POF. At the threshold temperature, the length of the fiber starts to shrink, which is mainly due to the release of the frozen-in stress induced in the fiber during the drawing process [22]. This shrinking is an irreversible process [22]. Temperature increases below the threshold can only result in a reversible decrease of the refractive index due to the negative thermo-optic coefficient (TOC, $-1.1 \times 10^{-4} /{ }^{\circ} \mathrm{C}$ ) of PMMA [24], which can be reversed to the original state once the temperature decreases [22].

Our experiments show that the blue shift of the resonance wavelengths, as shown in Fig.1 (b), was indeed reversible once the writing was stopped. Furthermore, we observed that the grating bandwidth did not change after the laser was turned off. From the grating growth dynamics in both annealed and non-annealed POF, the refractive index increase induced by the material compaction will always be companied by a local temperature increase, which actually decreases the refractive index because of the negative TOC of PMMA. Taking into account the refractive index change by UV-induced polymerization, UV-induced heating should increase the local temperature of POFs by approximately $15^{\circ} \mathrm{C}$ in order to have the $-0.15 \mathrm{~nm}$ blue shift of the resonance wavelength after 120 minutes of UV irradiation which is observed in Fig.1 (b). This scale of temperature increase is still far below the shrinking threshold [22] and will not result in any irreversible shrinking effect. The lack of further blue shift of the resonance wavelengths after 120 minutes can be explained by the POF reaching thermal equilibrium. The most significant difference between the POFs is the faster shift in resonance wavelength for the annealed POF. No significant change in photosensitivity of the fiber was observed after the annealing.

\subsection{Temperature characterization of FBGs}

The temperature response of the gratings was studied with the same monitoring setup as the one used during the grating inscription. The grating section of the polymer fiber was heated up with a resistive hot stage (MC60+TH60, Linkam). A thermo couple was used to measure the temperature as close to the grating as possible with an uncertainty around $0.3^{\circ} \mathrm{C}$. One end of the POF was clamped and butt-coupled to a silica fiber circulator, and the entire length of the POF with grating was attached to the surface of the heater by several layers of lens papers on the top. All gratings were fabricated with an exposure time of 60 minutes and they have similar peak intensities of about $-25 \mathrm{~dB}$.

Twenty minutes was allowed for the temperature of the grating to stabilize at each new setting before readings of the resonance wavelengths and peak intensity were taken. Firstly the gratings in the normal POF and the non-annealed POF were heated up separately from room temperature to $85^{\circ} \mathrm{C}$ stepwise in a single cycle, as shown in 
Figs. 2(a-b). In both gratings we observe a variation of the resonance wavelength and peak intensity, but no obvious bandwidth change was found. To investigate the operational temperature regime without hysteresis, the gratings were cycled 2 times by increasing the temperatures stepwise up to $55^{\circ} \mathrm{C}$ (non-annealed POF) and $75^{\circ} \mathrm{C}$ (annealed POF) at the first cycle and to the temperature $85^{\circ} \mathrm{C}$ (both) at the second cycle, which was followed by stepwise cooling down to room temperature after each cycle. The variation of the Bragg wavelength and peak intensity of the gratings with temperature for each cycle is shown in Fig. 3.
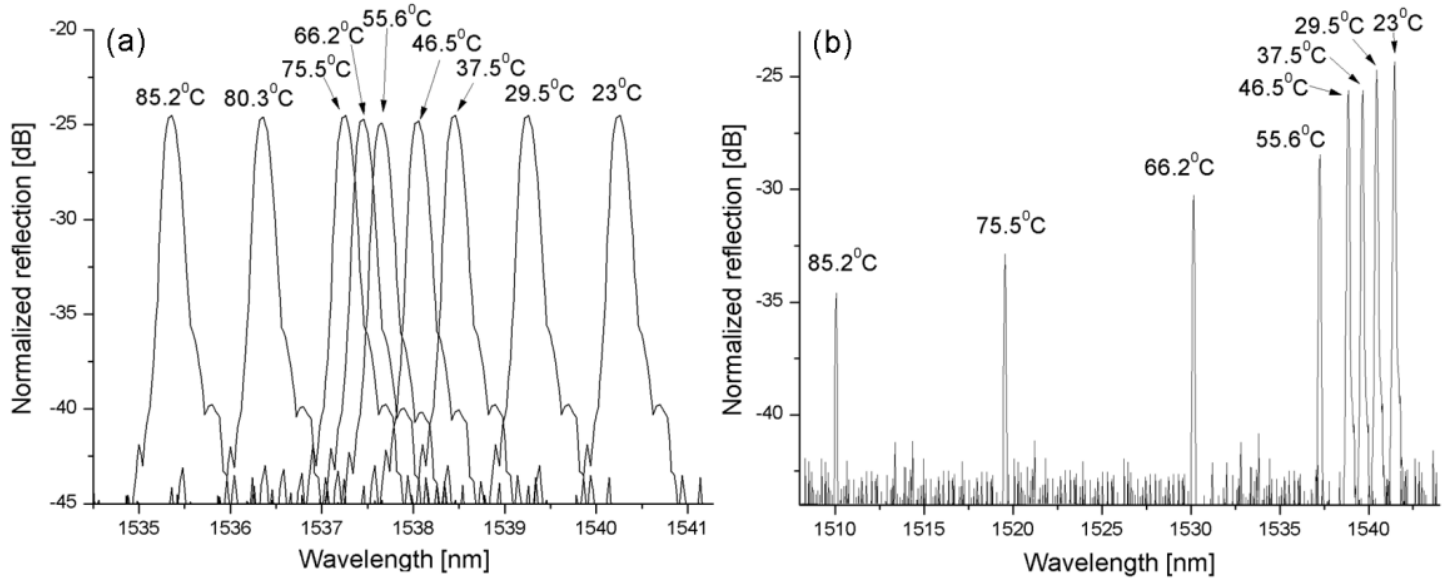

Figure 2. Reflection spectrum variation of Bragg with a consecutive heating cycle of temperature in the annealed POF (a) and the non-annealed POF (b).
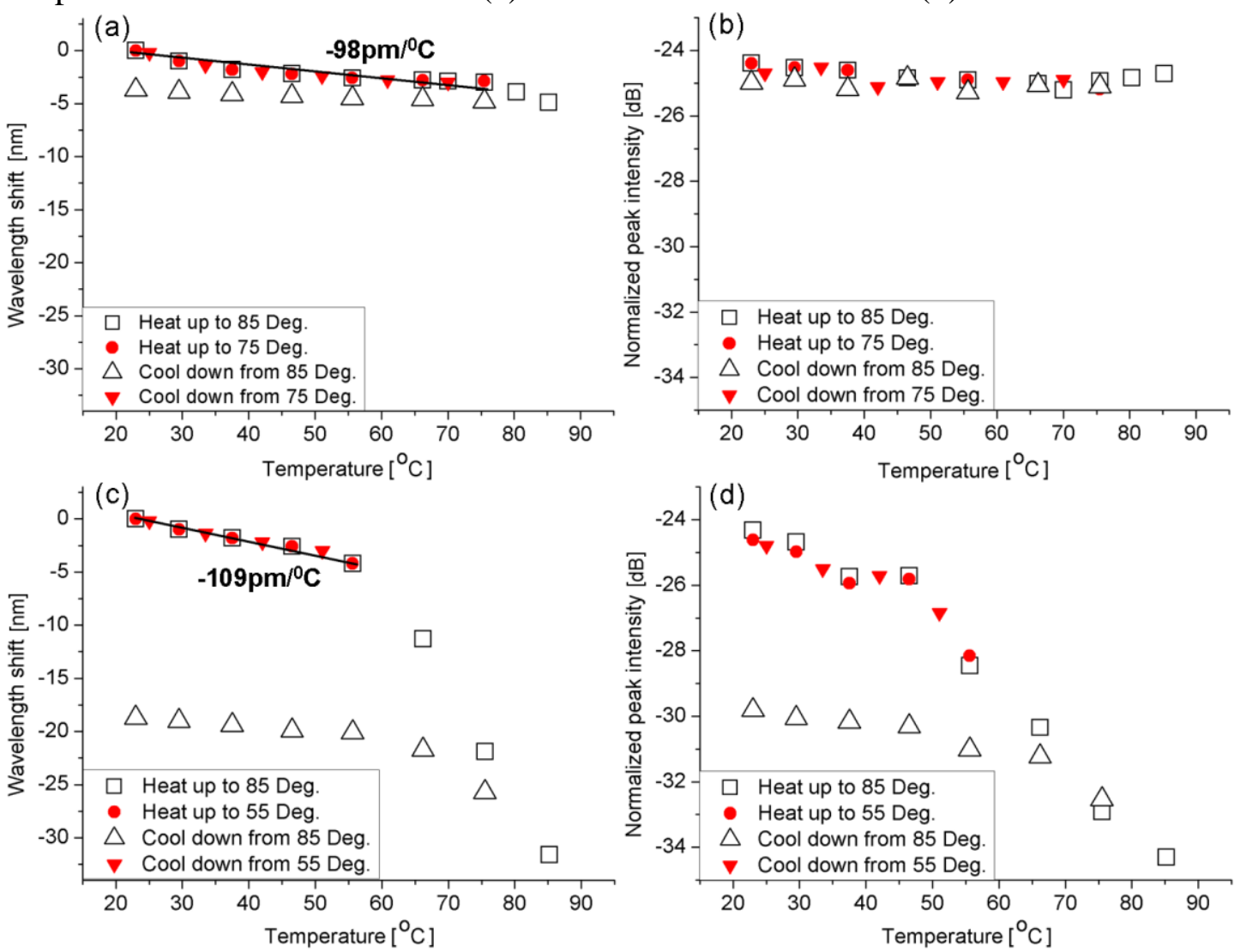

Figure 3. Bragg wavelength shift and peak intensity variation with temperature for two consecutive heating and cooling cycles in the annealed POF (a-b) and the nonannealed POF (c-d). The temperature response of the Bragg wavelength in (a) and (c) 
show an approximately linear thermal sensitivity of $-98 \mathrm{pm} /{ }^{\circ} \mathrm{C}$ and $-109 \mathrm{pm} /{ }^{\circ} \mathrm{C}$ for the annealed and non-annealed POF, respectively.

Hysteresis of the wavelength shift was observed once the temperature was taken to above the threshold, i.e., $75^{\circ} \mathrm{C}$ for the annealed POF grating and $55^{\circ} \mathrm{C}$ for the nonannealed POF grating. The temperature threshold is largely explained by the fiber shrinking and related to the thermal history of the fiber $[10,22]$. This hypothesis is supported by the different thermal thresholds of the annealed and non-annealed POF. When comparing with the non-annealed POF grating, the FBG in the annealed POF showed a higher operational temperature. This improvement is well-known and is mainly due to the releasing of the drawing-induced frozen-in stress by the annealing process [22]. Importantly, the annealed POF grating can provide a much more stable peak intensity during the temperature cycle below the threshold temperature, as shown in Fig.3 (b). In contrast, the FBG in the non-annealed POF experienced a constant yet reversible decrease of the peak intensity when the temperature was still lower than the threshold, as shown in Fig.3 (d). The results indicate that in the case of non-annealed POF grating the temperature increase would not only decrease the refractive index of the $\mathrm{POF}$, as indicated by the temperature response of resonance wavelength, but also probably decrease the index modulation of the FBG, which determines the strength of the grating, i.e., the peak intensity of its reflectivity. As shown in the Fig.3 (a) and (c), from the fitting of the quasi-linear part of the wavelength shift it can be found that the thermal sensitivitiy of both FBGs is almost the same. This means that the annealing process does not significantly change the TOC of PMMA.
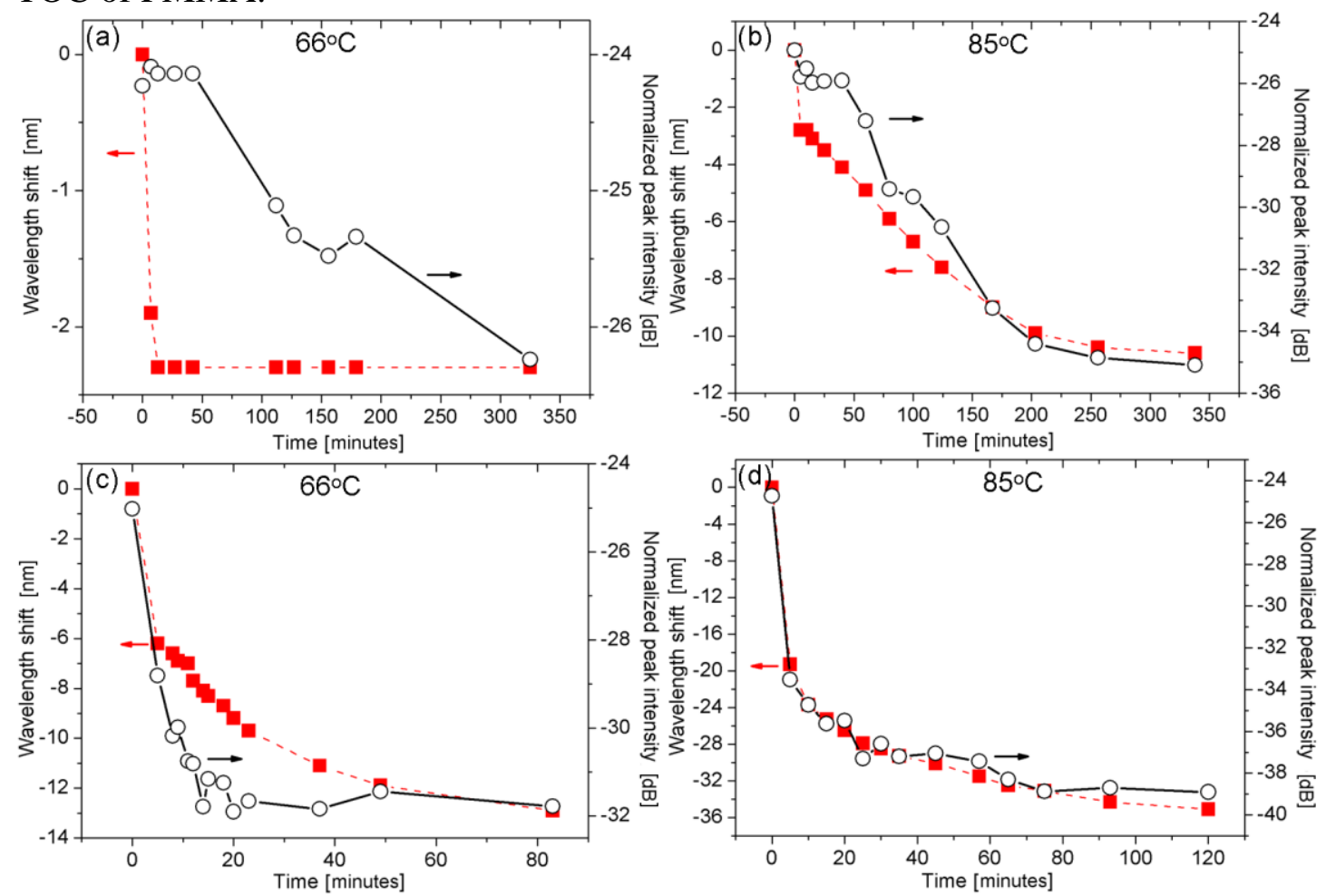

Figure 4. (a), (b) are thermal stability tests of FBG in annealed POF at $66^{\circ} \mathrm{C}$ and $85^{\circ} \mathrm{C}$ (c) and (d) show thermal stability of the FBG in non-annealed POF at the same temperature. Square-dash line represents the relative resonance wavelength of FBG, circle-solid line represents the normalized peak intensity of FBG. 
The fact that the annealing process does not eliminate the threshold totally can be further validated by the thermal stability experiments. As shown in Fig.4, the grating temperature was increased to and kept at $66^{\circ} \mathrm{C}$ and $85^{\circ} \mathrm{C}$ for both annealed and nonannealed POF. As demonstrated in Fig. 4 (b-d), it was found that both the resonance wavelength and the peak power of the gratings were varying during the monitoring time up to hours once the temperature was beyond the threshold. When the annealed POF grating was subject to $66^{\circ} \mathrm{C}$ and after the stable resonance wavelength reached, as shown in Fig.4 (a), no further wavelength shifting and only $2 \mathrm{~dB}$ peak power decrease was identified over 5.5 hours.

The unavoidable decrease of the peak power seen in Fig.4 would lead to the gratings being barely observable, especially if the temperature was above the threshold temperature of the gratings, i.e., $75^{\circ} \mathrm{C}$ for the annealed $\mathrm{POF}$ grating and $55^{\circ} \mathrm{C}$ for the non-annealed POF grating. We observed that when the grating was subject to a temperature beyond the threshold for hours its peak power could not recover to the original status after returning to room temperature (results not shown). In contrast, as shown in Fig. 3 (b), the annealed POF grating could resume to its original peak power after a short 20 minutes exposure to a temperature above its threshold $75^{\circ} \mathrm{C}$. This means that the long-term thermal stability of even the annealed POF FBGs is still a problem at high temperature.

\subsection{Tensile strain characterization of FBGs}
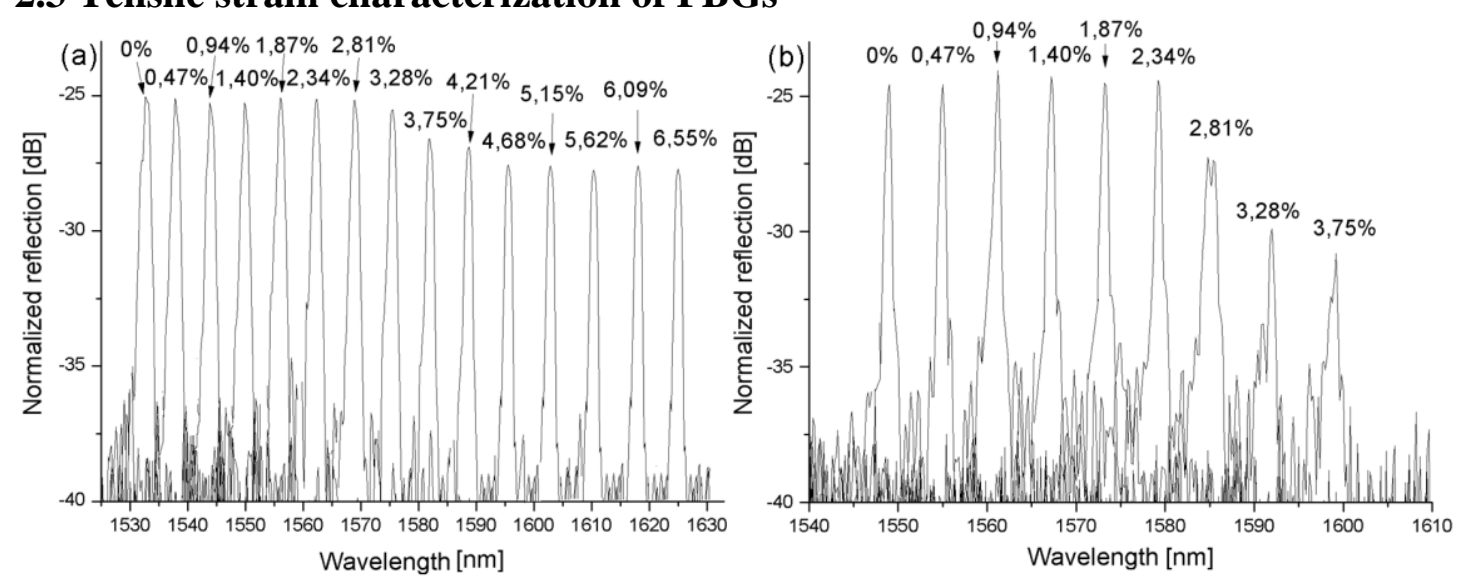

(c)
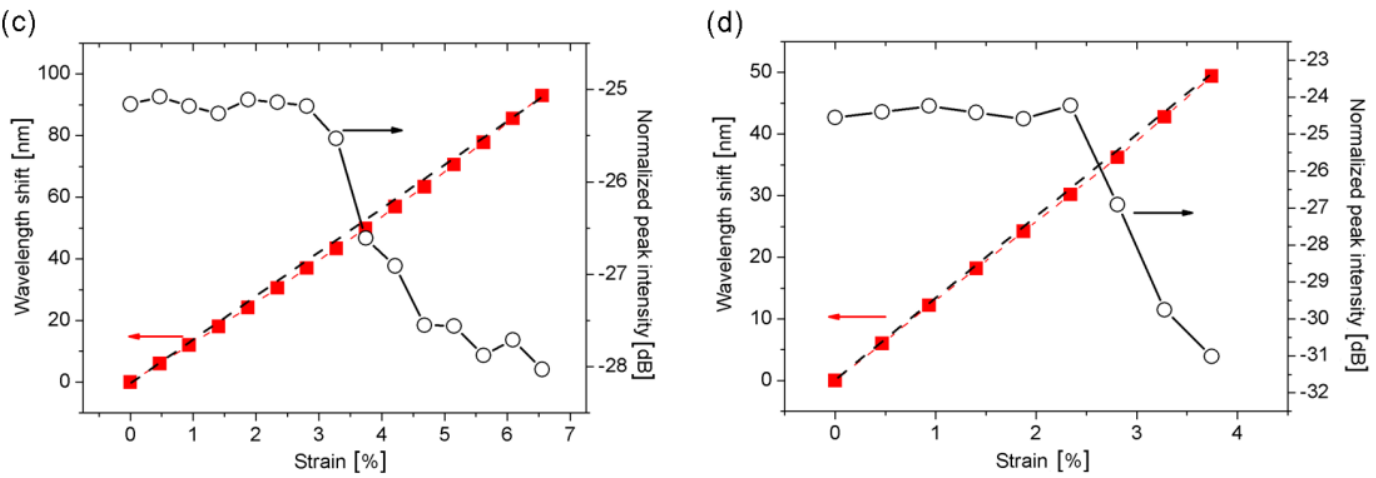

Figure 5. Single strain loading cycle of FBG in the annealed POF (a, c) and nonannealed POF $(b, d)$. $(a, b)$ : strained tuned reflection spectra, $(c, d)$ : the dash lines are the fitting of the Bragg wavelength shift. Squares-dashed line represents the relative resonance wavelength shift of FBG, and circles-solid line represents the normalized peak intensity variation of FBG. 
It is well-known that the annealing process would give a higher operational temperature of the POF FBGs. We are interested in accelerometers and fiber-optical microphones based on POF FBG strain sensor. This means that any improvement of the operational strain regime by annealing would be very important. The strain tuning of the polymer fibre Bragg gratings was investigated by mechanical stretching, and the strain characteristics of the gratings in both annealed and non-annealed POF were compared. The two ends of the POF were clamped to two micro-translation stages, with one of them fixed and used to butt-couple the POF to a silica fiber, and the other stage can move longitudinally to apply the axial strain to the grating manually with a very low loading speed. The axial strain values were determined by dividing the fiber longitudinal elongation by the length of fiber between the two clamping points. The longitudinal displacement accuracy of the moving translation stage is $0.01 \mathrm{~mm}$. All gratings were fabricated with the same exposure time, i.e., 60 minutes, which give them a similar peak intensity of about $-25 \mathrm{~dB}$.

The gratings were left to stabilize for about ten minutes each time the tensile strain was changed before reading the reflection spectrum. A single strain loading cycle experiment was carried out firstly to study the strain tuning responses of the two kinds of gratings, as shown in Fig. 5. As shown in Fig.5 (b) and (d), for the non-annealed POF grating, a strong decrease of peak intensity was found when the strain loading was taken over $2.5 \%$, and almost $7 \mathrm{~dB}$ peak intensity loss was introduced by the $3.75 \%$ strain loading, which was also accompanied by peak splitting [9], which made the grating peak very difficult to identify. As shown in Fig.5 (a) and (c), the strain tuning response of the annealed POF grating also showed a peak intensity decrease when the strain was over $2.81 \%$, but interestingly, the peak intensity only decreases 3 $\mathrm{dB}$ even when the applied strain was $6.55 \%$, which is more than twice the strain the non-annealed POF grating can hold. Furthermore, no peak splitting was found in the annealed POF grating even at strain up to $6.55 \%$.
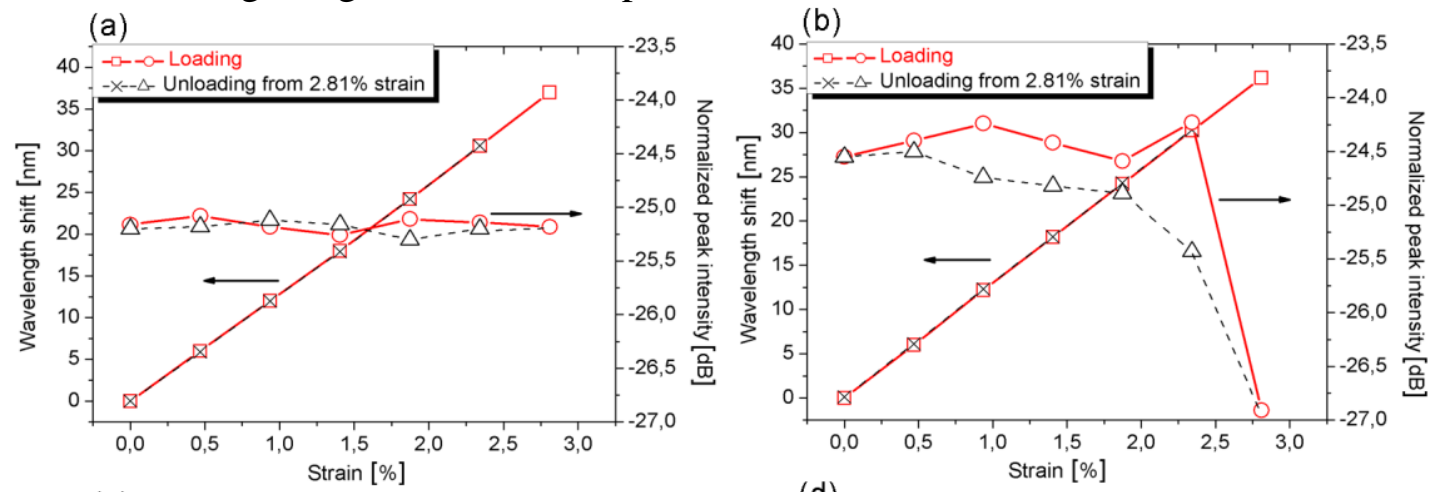

(c)
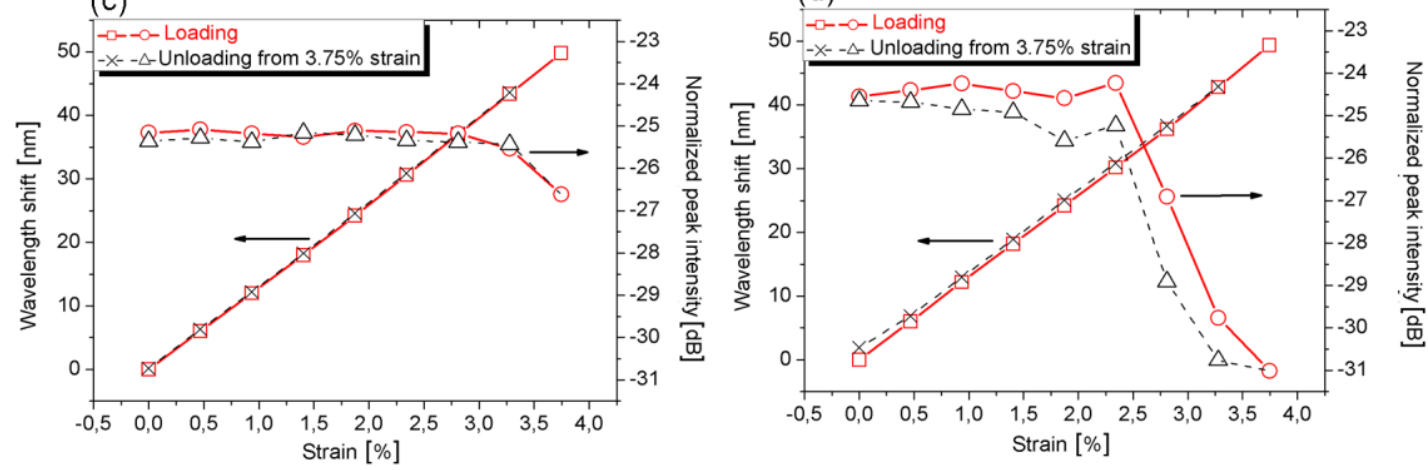

Figure 6. Strain tuning of FBG in the annealed POF (a, c) and non-annealed POF (b, d). Strain loading and unloading experiments at a maximum loading strain of $2.81 \%$ (a-b) and $3.75 \%$ (c-d). Squares-dashed line represents the relative resonance 
wavelength shift of FBG, and circles-solid line represents the normalized peak intensity variation of FBG.

Both gratings showed a quasi-linear response of the wavelength shift over the whole strain loading range. From the data fitting, it was found that the strain sensitivity of both gratings is similar, i.e., about $1.3 \mathrm{pm} / \mu \varepsilon$ for the non-annealed POF and about $1.37 \mathrm{pm} / \mu \varepsilon$ for the annealed POF. This is reasonable since the strain sensitivity only depends on the Young's modulus and geometric factors of the POF gratings. We think that the small difference of the strain sensitivity between two gratings is probably due to the small difference of the fiber diameter which has been induced by the shrinking effect of the annealing process.

The recoverability of the grating has been examined through the strain loading and unloading process, as shown in Fig.6. In the experiments, the strain was gradually applied to both gratings up to $2.81 \%$ and $3.75 \%$ separately and then gradually unloaded to zero strain. Judging from the variation of the resonance wavelengths and the peak intensities of the gratings during the loading-unloading experiment, as shown in Fig.6 (d), an observable hysteresis in the resonance wavelength appeared at a strain of $3.75 \%$ for the grating in non-annealed POF. For the annealed POF, in contrast, the grating was recoverable also at 3.75\% strain, as shown in Fig.6 (c). If we define the operational strain regime of POF FBG as up to where the peak intensity has decreased by $3 \mathrm{~dB}$ and the resonance wavelength is still recoverable, the experimental results showed that the operational strain range should be up to about $2.8 \%$ for the nonannealed POF grating and at least up to about $3.8 \%$ for the annealed POF grating.

Our experiments also showed that once the fibers were strained over threshold, for example, when strain was taken over $2.8 \%$ for the non-annealed POF grating or over $3.8 \%$ for the annealed POF grating, it took longer time for the gratings to stabilize and return to the original state when the strain was unloaded. The gratings did not return to their original states when the applied strain was over $3.75 \%$ for the non-annealed POF grating and over $6.55 \%$ for the annealed POF gratings even over 24 hours. This could be explained by that the gratings have been strained over their elastic limits.

The comparison of the two kinds of gratings through the strain tuning experiment showed that for the annealed POF there was a significant improvement in the stability of the peak intensity, no peak splitting at high loading strain was found and much higher strain can be applied to the fiber. As we mentioned before, the index modulation of the grating determines the grating strength, so the constant peak intensity means a much more stable modulation of index in the annealed POF grating under strain tuning. The unavoidable peak intensity decrease might be due to the increase of the mode propagation loss when the core of the fiber became smaller under the high longitudinal strain.

\section{Conclusions}

A detailed characterization of FBGs in commercial step-index POFs was presented. Through a study of the growth dynamics of the grating, the thermal effect of the UVinduced heating was shown to result in a reversible $0.15 \mathrm{~nm}$ blue shift in the resonance wavelength, which disappeared after the laser was turned off. We estimated the UV-induced increase in the temperature to be approximately $15^{\circ} \mathrm{C}$. This is below the damage temperature, which is why the blue-shift was reversible. Furthermore, no significant change in the photosensitivity of the POF was observed due to the annealing process before the grating writing. 
The thermal tuning experiments showed that hysteresis in the wavelength shift and peak intensity was observed once the temperature was taken to above a threshold, which was $75^{\circ} \mathrm{C}$ for the grating in the annealed POF and $55^{\circ} \mathrm{C}$ for the grating in the non-annealed POF. Comparing with the non-annealed POF grating, the grating in the annealed POF can offer a much more stable peak intensity during the temperature cycling below the threshold temperature. The similar thermal sensitivity of both gratings means that the annealing process does not change the TOC of the material significantly. The existence of a temperature threshold even after the annealing process was further validated by thermal stability experiments which showed a $10 \mathrm{~dB}$ drop in the reflected peak intensity over 6 hours at $85^{\circ} \mathrm{C}$, and it shows that the longterm stability of even the annealed POF FBGs is still a problem.

The strain tuning of the POF FBGs by mechanical stretching demonstrated that the operational strain limits without any hysteresis is $2.8 \%$ for the non-annealed POF grating and $3.8 \%$ for the annealed POF grating. The strain sensitivity of both the annealed and the non-annealed POF gratings is similar, which is about $1.37 \mathrm{pm} / \mu \varepsilon$ and about $1.3 \mathrm{pm} / \mu \varepsilon$, respectively. There was a significant improvement of the peak intensity stability, no peak splitting at high loading strain was found, and much higher strain can be applied to the annealed POF grating.

\section{Acknowledgements}

We would like to acknowledge support from the Danish National Advanced Technology Foundation.

\section{References}

1. M. Silva-Lopez, A. Fender, W. N. MacPherson, J.S. Barton, J.D.C. Jones,D. Zhao, H. Dobb, L. Zhang, I. Bennion, "Strain and temperature sensitivity of a single-mode polymer optical fiber," Opt. Lett., 30, 3129-3131, (2005).

2. K. Kalli, H.L. Dobb, D.J. Webb, K. Carroll, M. Komodromos, C. Themistos, G.D. Peng, Q. Fang, I.W. Boyd, "Electrically tunable bragg gratings in single-mode polymer optical fiber," Opt. Lett. 32, 214-216, (2007).

3. H. Dobb, K. Carroll, D. J. Webb, K. Kalli, M. Komodromos, C. Themistos; G. D. Peng, A. Argyros, M. C. J. Large, M. A. van Eijkelenborg, Q. Fang, I. W. Boyd, "Grating based devices in polymer optical fibre," Proc. SPIE., 6189, 1-12, (2006).

4. J.M. Yu, X.M. Tao, H.Y. Tam, “Trans-4-stilbenemethanol-doped photosensitive polymer fibers and gratings," Opt. Lett., 29, 156-158, (2004).

5. K. Kalli, H.L. Dobb, D.J. Webb, K. Carroll, C. Themistos, M. Komodromos, G.D. Peng, Q. Fang, I.W. Boyd, "Development of an electrically tuneable Bragg grating filter in polymer optical fibre operating at $1.55 \mu \mathrm{m}$," Meas. Sci. Technol., 18, 3155-3164, (2007).

6. M. Stecher, R.J. Williams, O. Bang, G.D. Marshall, M.J. Withford, G.E. Town. "Periodic refractive index modifications inscribed in polymer optical fibre by focussed femtosecond pulses," Proc. POF2009- The $18^{\text {th }}$ international conference on plastic optical fibers, (2009).

7. A. Baum, W. Perrie, P. J. Scully, M. Basanta, C.L. P. Thomas, N. J. Goddard, P. R. Fielden, P. R. Chalker, "Refractive index structures in poly(methyl methacrylate) and polymer optical fibre by femtosecond laser irradiation, OFS, (2006).

8. Z. Xiong, G.D. Peng, B. Wu, P.L. Chu, "Highly tunable Bragg gratings in single-mode polymer optical fibers," IEEE Photon. Technol. Lett., 11, 352-354, (1999).

9. H.Y. Liu, H.B. Liu, G.D. Peng, "Tensile strain characterization of polymer optical fibre Bragg gratings," Opt. Commun., 251, 37-43, (2005).

10. H.Y. Liu, G.D. Peng, P.L. Chu, "Thermal tuning of polymer optical fiber bragg gratings," IEEE Photon. Technol. Lett., 13, 824-826, (2001).

11. H.B. Liu, H.Y. Liu, G.D. Peng, P.L. Chu, "Strain and temperature sensor using a combination of polymer and silica fibre bragg gratings," Opt. Commun., 219, 139-142, (2003).

12. H.Y. Liu, G.D. Peng, P.L. Chu, "Polymer fiber Bragg gratings with $28-\mathrm{dB}$ transmission rejection," IEEE Photon.Technol. Lett., 14, 935-937, (2002). 
13. H.Y. Liu, H.B. Liu, G.D. Peng, P.L. Chu, "Observation of type I and type II gratings behaviour in polymer optical fiber," Opt. Commun., 220, 337-343, (2003).

14. G.D. Peng, P.L. Chu, X. Lou, R.A. Chaplin, "Fabrication and characterization of polymer optical fibers," J. Electr.Electron. Eng. Aust., 289-296, (1995).

15. H.Y. Liu, G.D. Peng, P.L. Chu, "Thermal stability of gratings in PMMA and CYTOP polymer fibers," Opt. Commun., 204, 151-156, (2002).

16. H.Y. Liu, G.D. Peng, P.L. Chu, Y. Koike, Y. Watanabe, "Photosensitivity in low-loss perfluoropolymer (CYTOP) fibre material," Electron. Lett., 37, 347-348, (2001).

17. D.J. Webb, K. Kalli, C. Zhang, M. Komodromos, A. Argyros, M. Large, G. Emiliyanov, O. Bang, E. Kjaer, "Temperature sensitivity of Bragg gratings in PMMA and TOPAS microstructured polymer optical fibres," Proc. SPIE , 6990, L9900-L9900, (2008).

18. E.E. Shafee, "Effect of photodegradation on the [beta]-relaxation in poly(methylmethacrylate)," Polym. Degrad. Stabil., 53, 57-61, (1996).

19. W.J. Tomlinson, I.P. Kaminow, E.A. Chandross, R.L. Forkland, W.T. Silvfast, "Photoinduced refractive index increase in poly(methylmethacrylate) and its applications," Appl. Phys. Lett., 16, 486489, (1970).

20. M.J. Bowden, E.A. Chandross, I.P. Kaminow, "Mechanism of the photoinduced refractive index increase in polymethyl methacrylate," Appl. Opt., 13, 112-117, (1974).

21. C. Jiang, M.G. Kuzyk, J. L. Ding, W. E. Johns, D. J. Welker, Fabrication and mechanical behavior of dye-doped polymer optical fiber, J. Appl. Phy., 92, 4-12, (2002).

22. K. Carroll, C. Zhang, D. J. Webb, K. Kalli, A. Argyros, M.C.J. Large, "Thermal response of Bragg gratings in PMMA microstructured optical fibers," Opt. Express., 15, 8844-8850, (2007).

23. D. Webb, K. Kalli, "Polymer fiber bragg gratings," in Chapter 15 of Book "Fiber Bragg Grating Sensors: Recent Advancements, Industrial Applications and Market Exploitation," edited by A. Cusano, A. Cutolo, and J. Albert, Bentham Science Publishers Ltd., 2009, 1-20.

24. M. C. J. Large, L. Poladian, G. Barton, M. Eijkelenborg, Microstructured polymer optical fibres, (Springer, 2008).

25. J. Jensen, P. Hoiby, G. Emiliyanov, O. Bang, L, Pedersen, A. Bjarklev, "Selective detection of antibodies in microstructured polymer optical fibers," Opt. Express., 13, 5883-5889 (2005).

26. A. Dupuis, N. Guo, Y. Gao, N. Godbout, S. Lacroix, C. Dubois, M. Skorobogatiy, "Prospective for biodegradable microstructured optical fibers," Opt. Lett. 32, 109-111 (2007).

27. G. Emiliyanov, J. B. Jensen, O. Bang, P. E. Hoiby, L. H. Pedersen, E. M. Kjær, L. Lindvold, "Localized biosensing with Topas microstructured polymer optical fiber," Opt. Lett. 32, 460-462 (2007).

28. G. Emiliyanov, J.B. Jensen, O. Bang, P.E. Hoiby, L.H. Pedersen, E.M. Kjaer, L. Lindvold, "Localized biosensing with Topas microstructured polymer optical fiber: Errat $\mu$ m", Opt. Lett. 32, 1059-1059 (2007).

29. A. Stefani, K. Nielsen, H.K. Rasmussen, O. Bang, "Microstructured polymer optical fibers cutting optimization and analysis," unpublished, (2010). 